\title{
Institutionalization of long-term care for the elderly: the experience of St. Petersburg
}

\section{G. V. Kolosova ${ }^{1}$}

${ }^{1}$ Herzen State Pedagogical University, 48 Moika River emb., Saint Petersburg 191186, Russian Federation

DOI: $10.18255 / 2412-6519-2021-2-194-203$

Research Article

Full text in Russian

The increase in life expectancy and the growth of the elderly population in the Russian Federation, including in St. Petersburg, dictates the need for changes in the areas of social services and health care. This is not surprising, aging today has become a global process that has different mechanisms of formation and differs by country and territory. But the sociological theoretical study of the topic of aging is still insufficient. European states rely on demographic trends, which determine a new approach to assessing the available resources, prospects for the development and improvement of social service systems in the direction of long-term care for the elderly. It is important, while maintaining continuity in the work of the social services established in the 1990s, to actively include the family, NGOs and volunteerism in the development of these institutions. The purpose of this article is to analyze the achievements and barriers to the institutional development of long - term care for the elderly in St. Petersburg. Methodically, the article is based on the analysis of legal acts regulating the development of long-term care, mainly in St. Petersburg. For the care system to take shape, it requires the participation of families, NGOs and volunteer resources, as well as the study of the best Russian and international experience.

Keywords: elderly; aging; social services; long-term care system; interaction; family care; volunteerism

\section{INFORMATION ABOUT THE AUTHORS}

\author{
Kolosova, Galina V. $\mid$ E-mail: kolosova@ksp.gov.spb.ru \\ (correspondence author) Postgraduate
}

For citation: Kolosova G. V. Institutionalization of long-term care for the elderly: the experience of St. Petersburg // Social'nye i gumanitarnye znanija. 2021. Vol. 7, No 2. P. 194-203. (in Russ.)

(C) Kolosova G. V., 2021

This is an open access article under the CC BY license (https://creativecommons.org/licenses/by/4.0/) 


\section{Институционализация долговременного ухода за пожилыми: опыт Санкт-Петербурга}

\section{Г. В. Колосова ${ }^{1}$}

1Российский государственный педагогический университет им. А. И. Герцена, наб. р. Мойки, 48 СанктПетербург, 191186, Российская Федерация

DOI: $10.18255 / 2412-6519-2021-2-194-203$

УдК 316

Научная статья

Полный текст на русском языке

Увеличение продолжительности жизни и рост численности пожилого населения в Российской Федерации, в том числе в Санкт-Петербурге, диктует необходимость изменений в сферах социального обслуживания и здравоохранения. Это неудивительно: старение сегодня стало глобальным процессом, имеющим разные механизмы формирования и различающимся по странам и территориям. Но социологическая теоретическая проработка темы старения пока недостаточна. Европейские государства опираются на демографические тенденции, которые определяют новый подход к оценке имеющихся ресурсов, перспектив развития и совершенствования систем социального обслуживания в направлении долговременного ухода за пожилыми. Важно, сохраняя преемственность в работе сложившихся в 1990-е социальных служб, активно включить в развитие этих институтов семью, НКО и добровольчество. Цель данной статьи - проанализировать достижения и барьеры институционального развития долговременного ухода за пожилыми в Санкт-Петербурге. Методически статья опирается на анализ нормативно-правовых актов, регулирующих развитие долговременного ухода в основном в Санкт-Петербурге. Чтобы система ухода сложилась, необходимо участие в ней семей, НКО и добровольческих ресурсов, а также изучение лучшего российского и международного опыта.

Ключевые слова: пожилые; старение; социальное обслуживание; система долговременного ухода; взаимодействие; семейный уход; добровольчество

ИНФОРМАЦИЯ ОБ АВТОРАХ

Колосова, Галина Владимировна $\mid$ E-mail: kolosova@ksp.gov.spb.ru

(автор для корреспонденции)

Для цитирования: Колосова Г. В. Институционализация долговременного ухода за пожилыми: опыт Санкт-Петербурга // Социальные и гуманитарные знания. 2021. Том 7, № 2. С. 194-203.

\section{Введение}

Увеличение доли и численности населения старших возрастов оказывает существенное влияние на социально-экономическое развитие «стареющих» государств. При этом население не только стареет, но и дольше живет. Ежегодно растет показатель ожидаемой продолжительности жизни при рождении. В Петербурге в 2019 году этот показатель составил 76,31 года (в России - 73,34 года), в том числе у женщин 79,99 лет (в России - 78,17 года), у мужчин 71,99 лет (в России - 68,24 лет). Относительно 2000 года показатель увеличился у женщин на 7 лет (с 73,02 до 79,99 лет), у мужчин - на 11,5 лет (с 60,44 до 71,99 лет) [1]. Несомненно, положительные демографические тенденции определяют новый подход к оценке имеющихся ресурсов, в том числе использования ресурсов самих пожилых.

(C) Колосова Г. В., 2021

Статья открытого доступа под лицензией СС BY (https://creativecommons.org/licenses/by/4.0/) 
Отметим, что до середины XX века научное сообщество не уделяло внимания старению населения, а удельный вес и численность пожилых людей длительное время не демонстрировали существенных темпов роста. Однако во 2-й половине XX века процесс старения населения стал очевидным. Восприятие пожилых людей в общественном сознании также изменилось. Определяющим в этом отношении становится изменение представления о возрасте старости и ее характеристиках, а также возникновение потребности в новых, долговременных, формах ухода. Но возраст старости в настоящее время отодвигается на 10-15 лет, численность пожилых растет, что порождает тревоги «кризиса старения» и нарушения демографического баланса [2]. Несмотря на важность демографических расчетов, они требуют социологической интерпретации, а изменение возрастной структуры общества - трансформации ряда социальных институтов. Представления о социально-возрастных группах как базовых категориях социального порядка все еще перегружены устойчивыми стереотипами, в то время как социальная жизнь быстро меняется, становится «текучей» [3]. Об институциональных сдвигах свидетельствует появление концепций «образования через всю жизнь» (life long education LLE) и «активного старения» (Active Ageing - AA), с одной стороны, и «долговременного ухода за пожилыми» (Long term care - LTC) - с другой. И если «активное старение» уже разработано как социологическая, а не только политическая тема [4], то «длительный уход» пока требует социологических и управленческих усилий [5].

В социологии проблематика изучения старения уже не нова, но пока только складывается, в отличие от социологии детства или молодости. Долгое время старение как «заключительный этап жизни» рассматривалось исключительно в медицинской парадигме, потом появилась наука «социальная геронтология», а социологии старения еще надо стать частью респектабельной теоретической социологии. Для этого должно быть больше работ о том, как социально-возрастная группа старших (людей позднего возраста) вписана в социальную структуру, как происходят процессы стратификации и дифференциации. По мнению ряда социологов, разные варианты геронтологии, например, критическая геронтология, старение на месте или старение как перспектива жизненного курса, относятся, скорее, к социологии возраста в целом, а не социологии старения [6].

В XXI в. пожилые, или, как в последние годы их называют, «старшие», уже не воспринимаются однозначно как объекты заботы и ухода. Напротив, все больше внимания уделяется изучению и использованию ресурсного потенциала старшего поколения, по возможности - стимулированию трудовой и общественной занятости пожилых людей. В этом направлении принимаются решения о продлении периода трудовой активности граждан после достижения пенсионного возраста. Приняты международные и российские нормативные документы, регулирующие, в том числе, трудовую деятельность пожилых людей: Мадридский международный план действий по проблемам старения $(2002)^{1}$ и в России «Стратегия действий в отношении пожилых» (2016) ${ }^{2}$. Государствам и работодателям эти документы рекомендовали создавать благоприятные условия и стимулировать занятость населения «третьего возраста».

\footnotetext{
${ }^{1}$ Political Declaration and Madrid International Plan of Action on Aging. Second World Assembly on Aging. April 8-12. 2002. Madrid. Spain. URL: https://www.un.org/en/events/pastevents/pdfs/Madrid_plan.pdf (дата обращения: 02.02.2021); Regional Implementation Strategy for the Madrid International Plan of Action on Ageing. UNECE Ministerial Conference on Ageing. September 11-13. 2002. Berlin. Germany. URL: https://www.unece.org/fileadmin/DAM/pau/RIS.pdf (дата обращения: 02.02.2021); Active Ageing: A Policy Framework. Geneva: World Health Organization, 2002. URL: https://apps.who.int/iris/bitstream/handle/10665/67215/WHO (дата обращения: 02.02.2021).

${ }^{2}$ Стратегия действий в интересах граждан старшего поколения в Российской Федерации до 2025 года. Утверждена распоряжением Правительства Российской Федерации от 5 февраля 2016 г. № 164-p. URL: https://rg.ru/2016/03/ 02/utverzhdena-strategiia-dejstvij-v-interesah-grazhdan-starshego-pokoleniia.html (дата обращения: 02.02.2021).
} 
Однако, сколь бы впечатляющими ни были успехи общества в деле увеличения продолжительности жизни и улучшения здоровья пожилых, определенная их часть все же на последнем отрезке жизни тяжело болеет и нуждается в долговременном уходе. Причем с увеличением продолжительности жизни растет и число нуждающихся в уходе. Перспективного развития и совершенствования требуют системы социального обслуживания и здравоохранения с учетом меняющихся потребностей и нужд пожилых, а также всех жителей Санкт-Петербурга.

Цель статьи - показать особенности складывающейся в Петербурге системы длительного ухода за пожилыми, проанализировать достигнутые успехи и барьеры во взаимодействии различных сложившихся и относительно новых социальных институтов в решении данной актуальной задачи.

\section{Методы}

Социология старения находится в ситуации «догоняющего развития», активно заимствуя статистические данные из социальной геронтологии, а подходы и методы - из социальной антропологии. При этом в дискуссии постоянно используется как объективистский подход структурных функционалистов, из которого, однако, вытекает, что быть пожилым - значит играть роль пожилого (как «роль больного» у Т. Парсонса), так и понимание того, что старение и его восприятие во многом социально и культурно конструируется (А. Мол). Обращение к анализу понятия телесной нормы (М. Фуко) тоже может быть плодотворным.

Автор использует анализ широко представленных в статье нормативных документов (качественную методологию) и анализ международных и российских статистических данных о старении в качестве дополнения. Анализируются федеральные законы и нормативные акты субъекта РФ (Санкт-Петербурга) разного уровня, касающиеся организации системы долговременного ухода (СДУ) за пожилыми. СДУ входит в корпус документов по организации социального облуживания в целом.

\section{Направления развития долговременного ухода}

Кто же нуждается в системе долговременного ухода? Кажется, ответ на данный вопрос очень прост - самые пожилые жители Петербурга. Однако и опыт, и результаты исследований показывают, что возраст и потребность в длительном уходе связаны не одномерно и не линейно. Это общая тенденция как для Западной Европы, так и для России. Так, в Западной Европе средняя продолжительность здоровой жизни женщин - около 74 лет, мужчин - 71 год. В России же у женщин - 68, а мужчин - 59 [7]. Нуждающихся в долговременном уходе (long term care) в России даже больше, чем в Европе из-за низкой продолжительности здоровой жизни. Идеолог создания системы долговременного ухода, руководитель проекта «Старость в радость» Е. Олескина отмечает: «С 2021 года внедрение СДУ проводится в 24 пилотных субъектах и стоит задача охватить СДУ 5,8 \% от числа граждан старше трудоспособного возраста и граждан с инвалидностью, нуждающихся в уходе» [8].

Система долговременного ухода (СДУ) - комплексная система, направленная на обеспечение каждого человека, не полностью справляющегося с самостоятельным уходом, системой поддержки самого высокого качества жизни с наивысшим возможным уровнем независимости, автономии, участия в деятельности, самореализации и человеческого достоинства. Традиционно длительный уход за пожилыми предоставлялся в интернатных учреждениях, т. е. домах престарелых. Но в настоящее время большое внимание уделяется стационарозамещающим технологиям ухода и обслуживания, 
позволяющим пожилому человеку оставаться дома, в привычной обстановке, как можно дольше.

Официальное определение долговременного ухода следующее: долговременный уход - технология социального обслуживания, в том числе стационарозамещающая, позволяющая обеспечивать посторонний уход за гражданами, нуждающимися в постороннем уходе, в целях обеспечения комфортных и безопасных условий проживания, сохранения (поддержания) самостоятельности и уменьшения зависимости от посторонней помощи таких граждан, их интеграции в общество [9].

Далее мы рассмотрим, в каких направлениях долговременный уход развивается в Санкт-Петербурге, где есть давние традиции взаимодействия власти и НКО, а также частных организаций в обслуживании пожилых.

\section{Варианты организации долговременного ухода в Петербурге}

Итак, учитывая, что население Петербурга - одно из самых пожилых в России, особое внимание в городе уделено созданию институциональной системы долговременного ухода за гражданами пожилого возраста и инвалидами, включающей сбалансированное социальное обслуживание и медицинскую помощь на дому, развитию стационарозамещающих технологий социального обслуживания. Федеральным проектом «Старшее поколение» национального проекта «Демография» предусмотрено введение СДУ в 85 субъектах РФ.

В Санкт-Петербурге внедрение предусмотренной приказом Минтруда России № 6671 Типовой модели системы долговременного ухода за гражданами пожилого возраста и инвалидами, нуждающимися в постороннем уходе, планируется в 2022 году. Исполнителями регионального проекта «Старшее поколение» являются Комитет по социальной политике Санкт-Петербурга совместно с 28 исполнительными органами государственной власти Санкт-Петербурга.

1. Адаптация сложившегося института обслуживания пожилых (КЦСОН) для развития технологий долговременного ухода.

С 2018 года на базе государственного бюджетного учреждения «Комплексный центр социального обслуживания населения Центрального района» создана экспериментальная (инновационная) площадка, на которой осуществлялась разработка модели отделения социально-медицинского обслуживания на дому граждан пожилого возраста и инвалидов (далее - ОСМУ). При формировании данной модели на первый план выдвигались повышение эффективности и активизация имеющегося потенциала клиентов, а также социально-психологический патронаж, улучшение качества адресной реабилитационной и оздоровительной работы с пожилыми людьми.

Эти меры способствуют сокращению повторных обращений пожилых граждан в стационарные учреждения здравоохранения, поскольку создаются условия, позволяющие сохранить возможность проживания пожилых людей и инвалидов в привычной домашней среде и способствующие повышению качества их жизни. Отделение организовано для предоставления ежедневного ухода на дому, чтобы обеспечить всестороннее удовлетворение потребностей получателя социальных услуг. Отличительной чертой проекта является увеличение коммуникативной и реабилитационной составляющей социального обслуживания.

\footnotetext{
${ }^{1}$ «О реализации в отдельных субъектах Российской Федерации в 2021 году Типовой модели системы долговременного ухода за гражданами пожилого возраста и инвалидами, нуждающимися в постороннем уходе». Приказ Минтруда России от 29.09.2020 № 667. URL: https://legalacts.ru/doc/prikaz-mintruda-rossii-ot-29092020-n-667-orealizatsii/ (дата обращения: 13.02.2021).
} 
На этапе апробации модели ОСМУ была сформирована группа клиентов из 22 человек и определен штат сотрудников: 15 работающих в отделении (заведующий, специалисты по уходу на дому и социальные работники) и привлекаемых (1-2 раза в неделю) специалистов других отделений (психолог, юрист, специалист реабилитационного отделения, специалист досугового отделения). Исследование показало, что среди получателей услуг инновационного отделения значительная доля граждан желает получать на дому услуги специалистов реабилитационного отделения. Также интерес граждан был проявлен к освоению информационно-коммуникационных технологий и к занятиям с психологом на дому. За месяц ОСМУ предоставляет в среднем 4 тыс. услуг. За время работы достоверно зафиксирована положительная динамика состояния получателей социальных услуг в части физической, эмоциональной и коммуникативной активности.

По результатам экспериментальной работы ОСМУ в 2019 году в 5 комплексных центрах создано 7 отделений социально-медицинского ухода на дому, служба сиделок и др. К 01.01.2021 года уже в 7 районах города работают 12 таких отделений. Социальные услуги долговременного ухода в 2019 году получили 209 чел.; в 2020 году - 303 чел. Затем пандемия COVID-19 несколько замедлила развитие. Но оптимизация деятельности отделений 18 комплексных центров социального обслуживания населения, находящихся в ведении администраций районов Санкт-Петербурга, будет продолжена в 2021 году.

2. Институционализация новой практики - создание службы сиделок

Законом Санкт-Петербурга от 21.12.2010 № 719-166¹ установлены дополнительные меры социальной поддержки отдельных категорий граждан по финансированию расходов, связанных с предоставлением услуг сиделок, в размере $90 \%$ от стоимости услуг за счет средств бюджета Санкт-Петербурга. В 2019 году услуги сиделок получили 437 чел., в 2020 году - 292 чел. С 01.01.2017 г. эти услуги включены в перечень предоставляемых поставщиками социальных услуг, утвержденный Законом Санкт-Петербурга от 26.12.2014 № 717-135². Услуги по социально-медицинскому уходу на дому (услуги сиделок) в 2019 году получили 2,5 тыс. чел., в том числе в негосударственных организациях - 1,9 тыс. чел.; в 2020 году - 5,3 тыс. чел., в том числе в негосударственных организациях - 2,9 тыс. чел.

Для развития экстренной помощи пожилым используется «тревожная кнопка», использование которой стало уже привычным. С 01.01.2017 г. данная услуга включена в перечень социальных услуг, предоставляемых поставщиками, утвержденный Законом Санкт-Петербурга № 717-135. Услугу «тревожная кнопка» в 2019 году получили 3,3 тыс. чел.; в 2020 году - 3,5 тыс. чел.

\footnotetext{
13акон Санкт-Петербурга от 21.12.2010 № 719-166 «О дополнительных мерах социальной поддержки отдельных категорий граждан по финансированию расходов, связанных с предоставлением услуг по социально-медицинскому уходу на дому». URL: https://peterburg-pravo.ru/zakon/2010-12-21-n-719-166/ (дата обращения: 13.02.2021). ²Закон Санкт-Петербурга от 26.12.2014 № 717-135 «О социальном обслуживании населения в Санкт-Петербурге» (с изм. и доп., вступившими в силу с 01.10.2019). URL: https://www.gov.spb.ru/static/writable /ckeditor/uploads/2019/11/27/22/zakon_SPb_717-135_red_04.07.2019_dei_01.10.2019 (дата обращения: 13.02.2021); Федеральный закон от 18.03.2020 № 60-Ф3. О внесении изменений в статьи 2 и 31.4 Федерального закона «О некоммерческих организациях». URL: www.kremlin.ru/acts/bank/45306 (дата обращения: 13.02.2021).
} 
Таким образом, как в долговременном уходе, так и в техническом оснащении ухода за пожилыми используются механизмы государственно-частного партнерства и расширяется взаимодействие с некоммерческими и частными организациями в соответствии

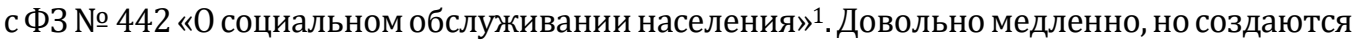
условия для вхождения негосударственных акторов на региональный рынок социальных услуг. Сегодня социально-ориентированные некоммерческие организации (СОНКО) могут получать статус исполнителя (поставщика) общественно полезных услуг в упрощенном порядке ${ }^{2}$, хотя определенные барьеры для их вхождения на рынок социального обслуживания существуют. По мнению социолога В.А. Смирнова, «Петербург является регионом с высоким уровнем развития некоммерческого сектора и социальных инноваций, что проявляется в самой большой доле успешных грантовых заявок СОНКО (почти 35 \%), а также высоком показателе победителей конкурса социальных проектов Фонда «Наше будущее» (ФНБ). Кроме этого, мы видим высокую степень включенности СОНКО в региональные рынки социальных услуг. Этот показатель выше, чем в Москве» [10].

3. Поддержка самого традиционного института заботы - семьи с нуждающимся в долговременном уходе

Исторически именно семья была основным институтом, осуществляющим долгосрочный уход за своими близкими, в том числе пожилыми. Однако в условиях индустриализации и урбанизации эта функция семьи реализуется все в меньшем объеме из-за вовлечения женщин в рынок внедомашнего труда. При этом сегодня в разных странах все чаще звучат призывы к деинституционализации ухода за пожилыми в последнем периоде жизни. Согласно распространенному мнению, дома можно поправиться быстрее даже в случае болезни (за исключением тяжёлых заболеваний). Кроме того, необходимо принимать в расчёт и тот факт, что содержание пожилых людей в больницах или специальных учреждениях намного дороже их проживания в домашних условиях. Долговременный уход, оказываемый квалифицированными специалистами на дому, в связи со всеми вышеперечисленными факторами оказывается более выигрышной стратегией. Не менее важным может быть и техническое оснащение квартиры пожилого человека различными сенсорными и мониторинговыми устройствами, позволяющими дистанционно получать информацию о его состоянии [11].

Мер поддержки семьи или ухаживающего за пожилым родственника пока недостаточно. Так, пенсионер по достижении 80 лет может обратиться в Пенсионный фонд за назначением ежемесячной компенсационной выплаты по уходу. Выплата составляет 1440-1560 рублей в зависимости от районного коэффициента. Выплата оформляется по месту нахождения пенсионного дела пожилого человека. Соответствующие заявления должны написать как пенсионер, так и ухаживающий человек.

Но есть ряд ограничений для ухаживающего. Осуществлять уход может человек:

- в возрасте от 14 лет и старше (при разрешении органов опеки);

- не работающий;

- не получающий пенсию;

- не получающий пособие по безработице.

«Плюсы» для ухаживающего - период ухода включается в трудовой стаж, а вот размер выплаты - 1200 р. - не менялся с 2002 г. Отсутствие позитивной поддержки очень

\footnotetext{
${ }^{1}$ Федеральный закон «Об основах социального обслуживания граждан в Российской Федерации» от 28.12 .2013 № 442-Ф3 (последняя редакция). URL: http://www.kremlin.ru/acts/bank/38016/ (дата обращения: 13.02.2021). ${ }^{2}$ Федеральный закон от 18.03.2020 № 60-Ф3. О внесении изменений в статьи 2 и 31.4 Федерального закона «О некоммерческих организациях». URL: www.kremlin.ru/acts/bank/45306. (дата обращения: 13.02.2021).
} 
сильно тормозит развитие семейного ухода, хотя и государство, и сами пожилые в нем заинтересованы.

В целях создания условий развития форм долговременного ухода, включающих социально-медицинскую помощь на дому, в том числе развитие форм родственного (семейного) ухода за пожилыми, Комитетом по социальной политике Санкт-Петербурга совместно с Комитетом по здравоохранению и администрациями районов города уже рассматривались предложения, подготовленные государственным бюджетным учреждением Городской информационно-методический центр «Семья» (далее - СПб ГИМС «Семья») по стимулированию родственного (семейного) ухода. Но конкретные решения по увеличению суммы выплат так и не были приняты.

Кажется, что ряд ограничений, отмеченных выше, должен быть снят для женщин предпенсионного возраста, ухаживающих за своими родителями или родителями мужа. Таким занятым домашним уходом женщинам необходимо сохранять трудовой стаж, а оплата их занятости также должна быть не меньше прожиточного минимума. Это, безусловно, меньше/дешевле, чем содержание пожилого человека в интернатном учреждении, соответствует, как правило, желаниям самих стариков и принципам гуманности.

Таким образом, инвестиции в оплату родственного ухода за детьми или пожилыми позволят избежать нового строительства и оборудования учреждений для ухода, найма воспитателей или сиделок и дальнейшей бюрократизации заботы. Это тем более оправдано, что в условиях наших демографических волн число необходимых мест в стационарных учреждениях то избыточно, то недостаточно.

4. Возрождение институтов солидарности - добровольчество

Солидаризации российского общества через развитие волонтерства придается сегодня большое значение [12]. При предоставлении долговременного ухода и комплексной медико-социальной помощи гражданам пожилого возраста добровольчество (волонтерство) также широко используется. Добровольцы предоставляют гражданам социально-бытовые, социально-педагогические, социально-правовые услуги, а также организуют мероприятия, посвященные памятным и праздничным датам, с посещением и поздравлением граждан на дому1.

Большую помощь комплексным центрам в работе с гражданами старшего поколения оказывают добровольцы (волонтеры) трудоспособного возраста. В 2020 году комплексными центрами социального обслуживания вовлечен в добровольческую деятельность 1451 чел., заключено 235 договоров с добровольцами (волонтерами) трудоспособного и пожилого возраста. Кроме того, СО НКО, работающие по направлению повышения качества жизни граждан пожилого возраста и инвалидов, активно вовлекают граждан в добровольческую деятельность.

Одной из организаций, деятельность которых в том числе направлена на развитие добровольчества в сфере социального обслуживания населения, является Межрегиональная общественная организация инвалидов и пенсионеров «Еврейский Благотворительный Центр «Забота - Хэсэд Авраам» (далее - «Хэсэд Авраам»). Данная организация занимается поддержкой, реабилитацией и защитой пожилых людей и инвалидов с 1993 г. В настоящее время в «Хэсэд Авраам» действует более 26 благотворительных

\footnotetext{
${ }^{1}$ Распоряжение Комитета по социальной политике Санкт-Петербурга от 26.04.2018 № 235-р (в редакции распоряжения от 28.07.2020) «Об организации и использовании труда добровольцев (волонтеров) в государственных учреждениях социального обслуживания населения Санкт-Петербурга». URL: https:/www.gov.spb.ru/static/ writable/ckeditor/uploads/2018/05/16/R\%20KSP\%2026.04.2018\%20№\%20235-p.pdf (дата обращения: 13.02.2021).
} 
программ, включая медико-социальную реабилитацию, дневной центр, программы помощи людям с синдромом Альцгеймера и их родственникам, предоставление проката реабилитационного оборудования и прочее.

В 2020 году «Хэсэд Авраам» продолжена реализация проекта «Терапевтические каникулы», в котором всю логистику, занятия с подопечными, сопровождение и развлекательную часть проводят сотрудники и волонтеры, прошедшие специальное обучение. Проект «Терапевтические каникулы» - это выездное мероприятие для пар «человек с деменцией - ухаживающий родственник», рассчитанное на 7 дней для оказания социально-психологической помощи семьям, столкнувшимся с проблемой деменции и долгосрочного ухода у своих пожилых родственников. В рамках мероприятия проходят тематические занятия: физкультурно-оздоровительные, лекции и мастер-классы, занятия, направленные на поддержание когнитивных функций подопечных, и многое другое.

В настоящее время большинство благотворительных программ ушло в онлайн и имеет постоянное расписание в разделе Хэсэд Онлайн. Терапевтические каникулы в 2020 году были Виртуальными терапевтическими каникулами. Кроме этого, впервые была проведена масштабная двухдневная конференция, посвященная проблемам деменции и болезни Альцгеймера. В ней приняли участие спикеры из Израиля, Германии, Нидерландов, Франции, Англии и Финляндии, было более 500 участников. Всего за 2020 год была оказана помощь более 12000 человек. Но на онлайн-мероприятия приходило за год более 30000 человек.

Начиная с 1993 г., когда был основан Хэсэд, аудитория получателей его услуг постоянно расширяется, а технологии обслуживания улучшаются в тесном взаимодействии с Комитетом по социальной политике Санкт-Петербурга и Ленинградской области.

\section{Заключение}

Итак, уже в настоящее время в Петербурге ведется активная работа по созданию системы СДУ, в которой принимают участие как Комитет по социальной политике СанктПетербурга и комплексные центры, так и ряд НКО и добровольных сообществ. Важным направлением работы с пожилыми можно считать работу по мотивации людей к длительной занятости, постепенное вытеснение мифологии пользы раннего выхода на пенсию доказательствами того, что потеря социального статуса травматична, приводит к ухудшению здоровья и ускоряет болезни и даже смерть. К сожалению, политическая толерантность не позволяет многим авторам-социологам прямо говорить об уходе на пенсию как пути в «социальное небытие». Занятость в разумном по продолжительности режиме вместе со здоровым образом жизни и доступностью восстановительной медицины гораздо полезнее пассивного «отдыха» на пенсии и отодвигает время, когда становится необходимым долговременный уход. Так, «молодые пожилые», т.е. люди от 55-60 лет до примерно 70 лет, могли бы взять на себя досуговую работу в комплексных центрах, проведение онлайн-занятий по реабилитационной физкультуре и психологическую помощь (по телефону) тем пожилым, которые уже редко выходят из квартир. Это было бы важным и почетным участием, добровольным или оплачиваемым, в институционализации СДУ.

Хотя Петербург не вошел в число пилотных регионов по внедрению СДУ, успешный опыт реализации мероприятий, направленных на развитие системы долговременного ухода в Санкт-Петербурге, неоднократно был представлен на международных форумах, региональных и городских конференциях. Традиционно в апреле 2019 года в Санкт-Петербурге прошел XIV Международный форум «Старшее поколение» (далее - 
форум), в рамках которого были организованы Международный конгресс «Социальная адаптация, поддержка и здоровье пожилых людей в современном обществе» и выставка социальной, медицинской, благотворительной помощи, товаров и услуг для пожилых людей «Забота, помощь, милосердие» и культурная программа. Более 21 тыс. посетителей форума привлекли выставочные экспозиции. В деловой программе форума приняло участие более 2,0 тыс. человек: представители органов социальной защиты населения из 44 субъектов Российской Федерации, специалисты из 11 зарубежных стран: Абхазии, Австрии, Белоруссии, Германии, Испании, Казахстана, Латвии, Молдавии, Монголии, Узбекистана, Финляндии. В 2021 г. Форум возобновит свою работу, прерванную в 2020 году в связи с пандемией Ковид-19, после улучшения эпидемиологической ситуации.

\section{Ссылки / References}

1. Численность населения Российской Федерации по муниципальным образованиям // Федеральная служба государственной статистики (Росстат). https://rosstat.gov.ru/compendium/document/13282?print=1 (дата обращения: 02.02.2021).

2. Вишневский А. Г. Демографический переход и проблема демографического саморегулирования. Ответ А. Б. Синельникову // Социологический журнал. 2019. Т. 25. № 4. C. 93-104. DOI: 10.19181/socjour.2019.25.4.6820.

3. Бауман 3. Текучая современность / Пер. с англ. СПб.: Питер, 2008. 240 с.

4. Григорьева И. А., Богданова Е. А. Концепция активного старения в Европе и России перед лицом пандемии Covid-19 // Laboratorium: журнал социальных исследований. 2020. № 12 (2). C. 187-211. DOI: 10.25285/2078-1938-2020-12-2-187-211.

5. Grigoryeva I., \& Sidorenko A. Eldercare in transition(S): The special case of Russia // International Journal of Care and Caring. 2019. № 3 (1). P. 59-73. https://doi.org/10.1332/239788218X15411704353873 (дата обращения: 02.02.2021).

6. Смолькин А. А. Социология возраста и границы социального конструирования // Социология власти. 2019 № 1 (31). C. 8-13. DOI: 10.22394/2074-0492-2019-1-8-13.

7. Long-term care in ageing societies - challenges and policy options. Commission staff working document. European Commission, 2013. URL:

http://ec.europa.eu/social/BlobServlet?docId=12633\&langId=en (дата обращения: 02.02.2021).

8. European Health for All Database (HFA-DB) // World Health Organization. Regional Office for Europe. URL: https://www.euro.who.int/en/data-and-evidence/databases/european-health-for-allfamily-of-databases-hfa-db (дата обращения: 02.02.2021).

9. Что будет с проектом системы долговременного ухода - комментируют Минтруд и БФ «Старость в радость». URL: https://www.miloserdie.ru/news/chto-budet-s-proektom-sistemydolgovremennogo-uhoda-kommentiruyut-mintrud-i-razrabotchiki/ (дата обращения: 18.03.2021).

10. Смирнов В. А. Региональные системы социального предпринимательства в России: типология, факторы развития, ключевые противоречия // Журнал исследований социальной политики. 2021. Т. 19. № 1. С. 23-40.

11. Meigal A., Korzun D. \& all. Ambient Intelligence At-Home Laboratory for Human Everyday Life // International Journal of Embedded and Real-Time Communication Systems. Volume 10. Issue 2. April-June 2019. URL:

https://pdfs.semanticscholar.org/4dee/e3874821494765f5b1cd08b6c1fac0d33da7.pdf (дата обращения: 18.03.2021).

12. Носкова О. П. Институт волонтерства как современная форма общественной солидарности на примере всероссийской акции \#мывместе // Социальные и гуманитарные знания. 2020. Том 6. № 4 (24). С. 368-379. DOI: 10.18255/2412-6519-2020-4-368-379. 